\title{
Literatura vasca e identidad nacional
}

\author{
MARI JOSE OLAZIREGI \\ Universidad del País Vasco/University of Nevada, Reno
}

\section{Un lema con el que empezar: «All for Our Country»}

Nevada, el estado norteamericano donde se encuentra el único centro de estudios vascos en el extranjero, el Center for Basque Studies de la University of Nevada en Reno, tiene por lema una frase que bien podría resumir la trayectoria de la literatura en lengua vasca hasta hoy: «All for our country». Al menos serviría para subrayar las motivaciones que muchos escritores vascos han esgrimido a la hora de explicar la elección de la lengua vasca o euskara para su creación. Y nos referimos al euskara, no solo porque la literatura escrita en esta lengua, o euskal literatura, conformará el eje de este artículo, sino porque precisamente el año pasado, año en que se celebró el «El año internacional de las lenguas», el debate en torno a las razones, funciones y motivaciones íntimas que llevan a los escritores vascos a elegir nuestra antigua lengua para vehicular su creación tuvo una vigencia y actualidad realmente inusitadas.

Y decimos inusitadas porque aunque sepamos que serán unas 3.000 las lenguas que desaparecerán en este siglo, parece ser que la lengua vasca tiene asegurada su supervivencia. Eso es al menos lo que se deduce de las afirmaciones de David Crystal en su conocido The Language Revolution (2004). El euskara cumpliría las condiciones socio-históricas necesarias que Crystal apunta como necesarias para asegurar la pervivencia, o para no engrosar la lista de los «endangered» languages» (lenguas en peligro de desaparición): nuestra lengua posee un número de hablantes considerable y claramente superior a los 100.000, una infraestructura política que, al menos en la Euskadi peninsular, defiende, subvenciona y legisla medidas para su promoción y normalización, tiene una presencia mediática y telemática considerable y, ante todo, es evidente que para muchos vascoparlantes, o euskaldunes, el euskara constituye su marca de identidad más esencial. La cuestión es que si el fantasma de la muerte del euskara está ahuyentado: ¿a qué razones responde hoy la creación en euskara?, o ¿cómo han determinado los pormenores sociolingüísticos la evolución de la literatura vasca?, ¿cómo se sitúa nuestra literatura en el panorama global actual? Éstas serán algunas de las cuestiones que inspirarán los puntos que siguen. 


\section{Inicios de la literatura en lengua vasca}

El libro de poemas: Linguae Vasconum Primitiae (1545) de Bernard Etxepare marcó el inicio de la literatura vasca. Tal y como han subrayado A. ArcochaScarcia y B. Oyharçabal (2008), se trata de un poemario cuyo paratexto manifiesta la ambición internacional del poeta: la elección del latín para el título y la constatación de que el libro incluye las primicias de la literatura vasca así lo corroboran. Animado por los beneficios que veía en la invención de la imprenta para la difusión de una literatura pequeña como la nuestra, Etxepare no dudaba en exclamar: «Euskara, Jalgi Hadi kanpora» (Euskara, sal fuera! Difúndete!) y manifestaba su claro deseo de que nuestra lengua tuviera un lugar en la República de las Letras. A partir de ahí, la poesía no sólo se erige en el género fundacional de nuestra literatura, sino en el género que abanderará la institucionalización de la literatura vasca, allá por 1950, como actividad autónoma dentro de la sociedad vasca.

En medio quedaban 400 años de una historia literaria dominada por un objetivo pastoral, una literatura protagonizada por religiosos, hombres, por supuesto, que tras el Concilio de Trento alimentaron el binomio euskaldun-fededun (vascoparlante $=$ creyente) que condicionó la producción literaria hasta finales del siglo XIX. Objetivos extraliterarios para una creación en lengua vasca que carecía de la infraestructura más elemental para constituirse en un sistema literario desarrollado. El listado de problemas a los que tuvo que hacer frente la literatura vasca incluye, entre otros, las dificultades para publicar en euskara (tres de cada cuatro libros fueron impresos fuera de las fronteras de Euskal Herria hasta 1700, o es conocido el ejemplo del libro Peru Abarka que tardó décadas en publicarse, allá por 1880), las prohibiciones para hacerlo, o la pérdida de publicaciones (cf. Mitxelena «Características generales de la literatura vasca», in Lertxundi: 2001). Todo ello perfila una situación donde uno de los elementos más fundamentales para la canonización y legitimización de textos literarios, el de la enseñanza en sus diferentes niveles, nunca se dio en euskara. Ejemplos como el de la Universidad de Oñati surgida en el siglo XVI, o el Real Seminario de Bergara, creado al amparo de las ideas de la Ilustración, son un exponente, en versión académica, de un mal endémico de nuestro pasado literario: el de haber tenido unos gobernantes que, incluso en la época de los fueros, jamás se preocuparon por el euskara, ni por la enseñanza y alfabetización en nuestra lengua. Cabe recordar que en el siglo XVIII el euskara es declarado «patois» en la zona vasco-francesa, y que en la Euskadi peninsular se aplicaron las leyes para la extensión de la escolarización en castellano (p. e. en 1780, se acató la obligación de la enseñanza de la gramática de la Academia Española). Es conocido el dato que aportaba Juan Ignacio Iztueta en su Guipuzcoaco provinciaren condaira (Historia de la provincia de Gipuzkoa, 1847). Según Iztueta, cinco de cada seis guipuzcoanos sabía euskara, pero la administración y la política se desarrollaba en castellano, por lo que sólo una sexta parte de los habitantes de la provincia de Gipuzkoa participaba activamente en la vida política de la época. Vida política ajena al mundo del euskara, vida literaria, tal y como ha defendido el profesor Lasagabaster (2005: 157), prácticamente inexistente en lengua vasca durante el siglo XVIII. Y es que la nómina de autores y obras que hoy incluimos en nuestra historia literaria no pertenecieron al sistema de la literatura vasca sino al de la ac- 
tividad pastoral y catequética de la Iglesia. La única vida estrictamente literaria del siglo XVIII se desarrolló a través de los Amigos del País, en la Real Vascongada y en el Real Seminario de Bergara antes mencionado, pero se dio, sobre todo, en castellano ${ }^{1}$.

Esta sucinta descripción de los inicios de nuestra literatura perfila un panorama en el que la situación diglósica de la lengua hace que nuestro pasado literario haya padecido o cumplido muchas de las características que Antón Figueroa describiera en su Diglosia e texto. La inclusión de obras no literarias en nuestra historiografía, la preeminencia de elementos folclóricos, míticos o etnográficos en la valoración de la mismas....son algunas de esas características. Se trata, en definitiva, de una literatura condicionada por los altibajos que la lengua que la sostiene, una literatura que hasta el último tercio del siglo XX no contó con un sistema literario consolidado.

\section{Euskadi, la patria de los vascos}

Lingüistas de la talla de Humboldt, o escritores como Wordsworth, Merimée, o Chamisso se sintieron atraídos por la lengua y la cultura vascas durante el siglo XIX. Pero, si hay un hecho que resultó decisivo para el devenir de la cultura vasca lo fue, sin duda, el del surgimiento, al amparo de las ideas románticas, de la ideología nacionalista. Sabino Arana proclamó que «Euzko tarren aberria Euzkadi da», es decir, que Euskadi (o Euzkadi, como dirá Sabino) es la Patria de los vascos. Ya para entonces, en 1847, Iztueta había establecido una equivalencia que sería determinante: la equivalencia entre los Fueros y el Euskara (Aldekoa 2004: 86), y otro autor, Agustín Chaho, se erigía con leyendas como la de Aitor (1847), precursor de la literatura histórico-legendaria que, cultivada en castellano por autores fueristas como Goizueta, Araquistáin o Villoslada, se fue filtrando a la poesía y narrativa en lengua vasca. Este linaje de Aitor (cf. Juaristi: 1987) creará el humus sobre el que el nacionalismo vasco erigirá esa immagined community (cf. Anderson: 1991) sostenida, como en la mayoría de los nacionalismos, «por una noble tradición que se remonta a tiempos inmemoriales» (Bhabba 1990: 45).

La revocación de los derechos forales tras la segunda guerra carlista, en 1876, fue el desencadenante de todo un resurgimiento cultural, Euskal Pizkundea

\footnotetext{
${ }^{1}$ A excepción del teatro popular suletino, los primeros documentos en la historia del teatro vasco son las piezas dramáticas de Xabier María Munibe e Idiaquez, Conde de Peñaflorida, que incluían algunas partes en euskara, y el Gabonetako Ikuskizuna de Pedro Ignacio Barrutia. No deja de ser curioso que en este panorama protagonizado por hombres, Peñaflorida firmara con un seudónimo femenino, Luisa de la Misericordia, el único texto que publicó íntegramente en euskara, el Gabon sariac, de 1792. ¿Era la transgresión lingüística sólo posible a través de una transgresión de género? La literatura vasca tendrá que esperar hasta 1804 para que la primera mujer, Bizenta Mogel con su Ipuin onak (Cuentos morales), adaptación de la fábulas de Esopo, entre en escena. Y Bizenta pedirá perdón en el prólogo del libro por el atrevimiento de publicar en una época, y en un contexto, el vasco, donde a una mujer no se le suponía esa afición. Aunque educada al amparo de las ideas de la Ilustración, Bizenta no asumió el destino que vaticinaban para la mujer algunos ilustrados de la época, el de la maternidad (cf. Martín Gaite 1981: 263), y pudo incorporar, aunque tímidamente, la voz de las mujeres a un panorama dominado, mitos del matriarcalismo vasco aparte, por hombres.
} 
(1876-1936), equivalente al Rexurdimento o a la Renaixença, donde la reivindicación patriótica vino de la mano de la reivindicación del euskara. A partir de aquí, la escritura en lengua vasca tendría por función primordial la de contribuir a la creación de la Nación Vasca. Al igual de lo que ocurriera desde la primera civilización letrada y literaria, la del conjunto de ciudades-estado sumerias en Mesopotamia, hasta los estados europeos como España, Francia, Italia o Alemania (Even Zohar 1993), también entre nosotros la literatura fue utilizada como factor omnipresente para la cohesión socio-cultural, es decir, para el establecimiento de una identidad y nación, la vasca. Es la época en la que de la mano de los Juegos Florales, la publicación de Cancioneros, o el impulso de los estudios filológicos se trató no sólo de ahuyentar el fantasma de la muerte de la lengua, sino de convertirla en vehículo de expresión culta acorde con los tiempos. El debile principium melior fortuna sequatur con el que clausuró su libro Etxepare en 1545 no tuvo su continuación más certera hasta que otro poeta, Xabier Lizardi, allá por la década de 1930, nos volviera a señalar en su «Eusko-Bidaztiarena» (Canción del viajero vasco) la tarea primordial de la literatura vasca: la de convertir el idioma rústico en una lengua versátil y culta (Lertxundi 2001: 48). Para entonces, la literatura escrita en lengua vasca ya había empezado a crear sus «Otros»: los personajes que no se correspondían con el esterotipo de euskaldun $=$ fededun $=$ baserritarr $a($ vascoparlante $=$ creyente $=$ campesino $)$, estereotipo creado por la narrativa costumbrista que imperará hasta mediados del siglo XX. Y es que, al hilo del concepto Nación surgido a partir del siglo XVIII, también el nacionalismo vasco era esencialista y cumplía las características que definieron idealistas alemanes como Fichte. Los inmigrantes castellanoparlantes que poblaron las ciudades industriales vascas desde finales del XIX, o todos aquellos euskaldunes que renegaban de la fe católica y no seguían el nacionalismo tradicional conformarían la lista de los «Otros» que fue creando la ficción de nuestro novelista más representativo de la época: Domingo Agirre. Junto a estas representaciones literarias, la literatura vasca tuvo sus «Otros» más reales en los escritores vascos que, como Miguel de Unamuno, no sólo no escribieron en euskara, sino que osaron vaticinar su desaparición por su supuesta incapacidad para adaptarse a los tiempos modernos. El caso de otro escritor vasco, Pío Baroja, resulta más que significativo por la valoración que desde la institución literaria vasca ha merecido. La celebración del cincuentenario de su muerte en 2006 sirvió de excusa no sólo para la organización de jornadas o lecturas en conmemoración de su obra, sino para que se publicaran las traducciones de Zalacaín el aventurero, o El árbol de la ciencia, y un libro, Pío Baroja, 50 urte [Pío Baroja, 50 años] (Serrano Izko, B. et al, 2007), donde la crítica literaria en lengua vasca pudo ratificar el magisterio de la narrativa de Baroja, su «mirada» cálida hacia la realidad vasca ${ }^{2}$.

2 Se trataba de saldar viejas deudas pues, a excepción de críticos como J.M. Lasagabaster (2002), pocos estudiosos de la literatura vasca contemporánea han subrayado la oportunidad que perdió la narrativa vasca de la primera mitad del siglo Xx para desterrar una poética costumbrista trasnochada y próxima a autores como Pereda, e inspirarse en el estilo realista de Baroja. Dicho giro habría permitido sustituir, entre otros elementos, el mundo maniqueo que reinaba en la narrativa costumbrista vasca de la época e incorporar a la literatura escrita en lengua vasca personajes próximos a los fascinantes barojianos Maribelcha, Teillagorri, o Zalacaín. 
La poesía post-simbolista tuvo su mejor expresión en la obra de Jose María Agirre, «Lizardi» y de Esteban Urkiaga, «Lauaxeta». Ambos fueron nacionalistas y participaron activamente en el segundo renacimiento cultural, Euzko Pizkundea, que se dio durante los años de la II República, años en los que el activismo político nacionalista y cultural fueron de la mano. Ambos pertenecieron a la asociación Euskaltzaleak que, a partir de 1930, intensificó sus actividades y persiguió una producción literaria que diera prestigio a la cultura en lengua vasca. Alentados por el polifacético José Aristimuño, Aitzol (cf. Otaegi 2007), se trataba, ante todo, de ahuyentar de nuevo el fantasma de la desaparición de la lengua y de mostrar que el euskara podía ser lengua creadora de una literatura de calidad, una literatura que buscó sus referentes en poetas simbólicos canónicos. Pero ni la lengua utilizada (Lizardi y Lauaxeta seguían las normas puristas dictadas por Sabino Arana), ni la poética elegida, ayudaron a conectar con un lectorado vasco reducido y cuyos hábitos de lectura en euskara eran casi inexistentes. La Guerra Civil española, la consecuente represión que siguió a ella, la censura y prohibición para publicar en euskara, frenaron el avance literario que se dio con los poetas de la II. República. Para la política lingüística franquista el euskara no tuvo rango cultural (cf. Torrealdai 1999: 16).

Creemos que la aparición del escritor Gabriel Aresti, no sólo sirvió para que la literatura escrita en lengua vasca entrara de lleno en la modernidad, sino para afirmar que escribir en euskara respondía a razones que superaban el estricto compromiso nacionalista. La afirmación de que el euskara era su patria y un rasgo fundamental de su identidad vasca, viene avalada por declaraciones tan contundentes como las realizadas en 1960: «El euskara es una necesidad para mí. ¿Quién dice que ama el pan? El pan no se ama, se necesita. Es lo que me ocurre con el euskara: no lo amo, lo necesito» (Aresti 1986: 26). Son declaraciones que en boca de un euskaldunberri, es decir, una persona cuya lengua materna no fue el euskara resultan significativas por el deslinde que supone del ideario nacionalista. La voz profética de Aresti viene impregnada de la tradición occidental cimentada por textos como la Biblia, y la Divina Comedia, textos que Eliot supo adaptar a la desazón de los tiempos modernos. Y ese Aresti que recreó literariamente la gran metrópolis vasca, Bilbao, la Euskadi multicultural y diversa que había sido marginada en la literatura vasca, publicó, en 1964, Harri eta Herri (Piedra y Pueblo, 1964), uno de los pocos libros de nuestra historia reciente que sí que podemos afirmar que conectó con los lectores vascos. Seguramente, el euskara «klarua» (claro) que utilizara el poeta, un euskara alimentado por nuestra literatura clásica y por la literatura oral, tuvo mucho que ver en ello. Su lengua estará próxima a lo que años más tarde, en 1968, La Real Academia de la Lengua Vasca impulsaría de la mano del insigne lingüista Koldo Mitxelena ${ }^{3}$.

${ }^{3}$ No fueron años fáciles, a juzgar por los arduos debates que marcaron la década de los 1950 y 1960 entre los que se autodenominaban vascófilos (próximos al nacionalismo tradicional de Arana, y a la revista Euzko Gogoa, entre otros), y los vascólogos (encabezados por Mitxelena y que abogaban por un euskara «vivo», frente a uno «puro»). Para Mitxelena, al igual que para Aresti, ser vascoparlante se anteponía a ser «vasco» en el sentido esencialista de Arana. 


\section{«Tú eres mi patria». Utopías e identidades permeables}

Aresti afirmaba en 1966, en una conferencia que impartió en Barcelona invitado por los universitarios vascos, que la juventud de la época era una juventud triste y preocupada (Aresti, 1986: 71). Esa juventud incluía, sin duda, a los escritores que junto él habían creado la editorial Lur (1964) en Donostia y cuyo lema era «Lur: Kultura Herriarentzat» (Lur: Cultura para el pueblo). Pero escribir para el pueblo significaba en aquel entonces publicar una literatura que hacía suyas las premisas del Modernism, una literatura que buscaba otra vuelta de tuerca en el afán por conectar con las tendencias europeas del momento. Ramón Saizarbitoria, uno de sus integrantes más conocidos, irrumpió en el panorama literario vasco a finales de los años 60 publicando novelas experimentales próximas al Nouveau roman, pero asumiendo que lo hacía por la «construcción nacional» (Etxeberria 2002: 103). Eran años de militancia cultural, militancia que llevaba a algunos a comprar libros en euskara aunque no tuvieran la competencia lingüística suficiente para leerlos (Etxeberria 2002: 113). Años en que obras como el Quosque Tandem (1963) de Jorge Oteiza, aunaron vanguardia artística e ideología de izquierdas. Oteiza hablaba del estilo vasco, del alma vasca formada en el Neolítico... pero el eje de su identidad no era el euskara. Por eso chocó con Aresti (Aresti 1986: 74), y por eso su influencia en la literatura vasca (a excepción de algunos poetas que empezaron a publicar en la década de los 60 , tales como Lekuona, Gandiaga o Artze) no ha sido tan reseñable como se esperaba.

Llegados a este punto, deberíamos continuar diciendo que el canon de la literatura vasca actual lo conforman autores que continuaron-subvirtieron la trayectoria poética de Aresti. Sea los que fueron próximos a Lur (Saizarbitoria, Urretabizkaia), sea los que se denominaron como la generación de la «Autonomía Literaria», liderada por la Banda Pott (1978-1980) (Atxaga, Sarrionandia...), o los que ampliaron el espectro de géneros y poéticas durante el boom editorial de la década de los 80 (Landa, Lertxundi ...), todos ellos optaron por escribir en euskara y lo convirtieron en eje de su identidad vasca (y literaria). La biografía de casi todos ellos habla de una lengua «ganada» para la literatura tras haberla aprendido o «recuperado» (cf. Etxeberria: 2002; Urkiza: 2006). De una biografía marcada en la mayoría de los casos por un ámbito, el familiar, vascoparlante y un ámbito, el público, castellano. Una esquizofrenia lingüística que ha resultado problemática en opinión de algunos ${ }^{4}$, pero que concibe la creación literaria unida irremediablemente al euskara. ${ }^{5}$

${ }^{4}$ Ramon Saizarbitoria hablaba de una «incapacidad lingüística disimulada» (1999: 21) a propósito del uso del castellano en algunos momentos críticos de su novela Hamaika pauso (1995. Trad.: Los pasos incontables, Espasa, 1998). El protagonista, Daniel Zabalegui sabe que al día siguiente va a ser fusilado y decide escribir un texto. No puede hacerlo en euskara y recuerda el caso del poeta Esteban Urkiaga, Lauaxeta, que la víspera de ser fusilado escribió también en castellano.

${ }^{5}$ Resultan reveladoras las motivaciones y razones íntimas que aducen algunos de los escritores contemporáneos vascos a la hora de comentar su opción lingüística a favor del euskara. Koldo Izagirre, menciona, por ejemplo, que se reencontró con el euskara en su primera adolescencia y que «Si no me hubiese euskaldunizado, seguramente hoy no sería escritor» (in Etxeberria 2002: 248). Para Atxaga, en cambio, la escritura en euskara es un acto más natural, se trata de la lengua que 
Es el deseo de superar el binomio nacionalismo-euskara el que protagoniza la escritura en lengua vasca actual, y ese deseo se ha visto plasmado en la literatura más reciente. Cuando el protagonista de la última narración de Gorde nazazu lurpean (Guárdame bajo tierra) (2000), de Ramón Saizarbitoria, dice a su compañera: «Tú eres mi patria» y lanza las reliquias del padre del nacionalismo vasco, Sabino Arana, al mar, no hace otra cosa que desprenderse de la pesada carga ideológica heredada de su padre y situarse en una posición que le permita vivir, es decir, aceptar su castración y hacer frente al deseo. El incremento de narraciones que toman como eje temático nuestro pasado histórico más reciente, narraciones que en forma de metaficciones historiográficas o de novelas históricas actualizadas tratan acontecimientos como la Guerra Civil y la posguerra, o el terrorismo de $\mathrm{ETA}^{6}$, son ejemplo de esa necesidad que la literatura vasca tiene de releer y deconstruir los discursos monológicos que desde posiciones políticas diversas (nacionalismo vasco, nacionalismo español), han construido discursos identitarios excluyentes. Y es que, como afirmaba J.W. Müller (2002:1) «Memory matters.» Hablamos de una recreación del pasado como factor de identidad, una recreación que ha tenido consecuencias éticas, filosóficas, pero, ante todo, políticas, pues es obvio que las comunidades nacionales que han visto cuestionado su ser han encontrado en esa recuperación del pasado histórico una salida para su hasta entonces negada especificidad. Memoria como antídoto a la nueva utopía de la globalización, memoria como anclaje a la realidad y contrapartida al espacio hiperreal, memoria, en definitiva, como eje de nuevos mapas étnicos (Müller 2002: 13-18) ${ }^{7}$. Es en este contexto donde podemos situar a novelas paradigmáticas como Soinujolearen semea (El hijo del acordeonista) (2003), de Bernardo Atxaga. El bombardeo de Gernika, los terribles fusilamientos y desapariciones de la posguerra, o el estallido de la violencia terroris-

conforma su mundo más próximo, mundo en el que su familia, amigos, la gente de su generación está implicada (in Altan 2007: 40). Qué diferente esta última reflexión de la que otro escritor, Antonio Muñoz Molina, ofrece en la misma publicación. El escritor andaluz afirma que el español: «est la langue du monde clos et familier dans lequel j'ai vu le jour, et en même temps une langue universelle dans laquelle je puis échanger des idées avec mes semblables jusqu'au bout du continent américain» (Altan, op. cit., p. 59) y completa sus afirmaciones declarando: «Dans mon pays, dans l'Europe entière, on n'entend plus qu'éloges, souvent passablement dithyrambiques, des différences, des identités, de l'authenticité, des cultures au sens anthropologique, des langues qui s'affirment ou son à protéger. Je crois qu'il serait temps de mettre en évidence ce qui nous unit en tant que personnes et citoyens libres. Il faut en finir avec cet orgueil de nos origines. Comment quelqu'un peut-il tirer vanité de ce qu'il est, se prévaloir de ce qu'il a reçu par le hasard de naissance? Si j'aime ma langue ce n'est pas parque qu'elle me appartient (...) mais parce qu'elle me permet de communiquer avec un grand nombre de manière fine et nuancée» (Altan op. cit., p. 62). Sobran los comentarios.

${ }^{6}$ Creemos que el cuento «Bibliografía», de Iban Zaldua, reflexiona con acierto sobre la dolorosa realidad política vasca (cf. Pintxos. Nuevos cuentos vascos, Lengua de Trapo, 2005). Huyendo de planteamientos maniqueos, Zaldua ha sabido transmitir que la realidad vasca, como toda realidad, es un constructo de lenguaje que admite muchas lecturas, tantas como ese libro que se erige en protagonista último del relato. La diferencia radica en que esa realidad tiene sus víctimas, unas víctimas que llevan nombres y apellidos y que quiebran cualquier intento de distancia ficcional.

7 A propósito de la recuperación histórica en algunas obras de Ramon Saizarbitoria, véase mi artículo: «Mapping the Nation in Contemporary Basque Literature» (Anuario del Seminario de Filología Vasca «Julio de Urquijo». Fecha prevista de publicación: 2009). 
ta en la década de los años 60 planean sobre el cielo de Obaba. Y de nuevo, la restitución del pasado tiene una función ética en un texto de Atxaga, pues vuelve a recordarnos que la Historia es un discurso narrativo que ofrece una interpretación (cf. Foucault, o White); una interpretación hecha, por supuesto, desde el lado de los vencedores. En El hijo del acordeonista, Atxaga vuelve a hablar, como en El hombre solo, o en Esos cielos, de destierros, de sujetos que tratan de construir su casa fuera de casa. Pero esta vez en vez de espacios heterotópicos (un hotel, la cárcel), prevalecen las utopías, la posibilidad de volver a empezar. Tal y como demostró Gorka Mercero (2006), el concepto de Nación que refleja la novela de Atxaga no se corresponde con un concepto esencialista, sino con uno diferencial, más próximo a lecturas contemporáneas como la realizada por Jacques Derrida. El poema que inicia El hijo del acordeonista, «Muerte y vida de las palabras», así lo atestigua: «Así mueren/las palabras antiguas:/como copos de nieve...». El poeta remata el texto afirmando que nuevas palabras se alzan al cielo en boca de las generaciones del futuro. Utopía y esperanza, también presente en conceptos atxaguianos como el de «Euskal Hiria» (Ciudad Vasca), una ciudad del futuro donde la convivencia de todos los vascos sea posible..., también en euskara (euskal) (cf. «Otra mirada» en www.atxaga.org).

La utopía de Atxaga expresa un deseo de convivencia futura, una convivencia que momentáneamente se antoja difícil. Pero lo que todavía no se ha erigido en centro de un debate profundo entre los vascos es la cuestión de la identidad múltiple, es decir, la que debe llevar a la aceptación, como decía Paddy Woodworth (2007), de que varias lenguas nos habitan. Amin Maalouf, en su conocido Identidades asesinas, afirmaba que es posible estar a caballo entre dos lenguas, dos tradiciones, vivir una extraterritorialidad que se erige en constitutiva de una identidad. Ese «In Between» del que hablaba Homi Bhabha en The Location of Culture (1994). Aunque es verdad que muchos escritores vascos contemporáneos admiten que el castellano o el francés también son parte de su cartografía identitaria (Landa, Arkotxa, Zaldua, Elorriaga...), lo cierto es que el debate que recientemente ha surgido a raíz de la publicación en castellano de la autobiografía de Mariasun Landa, La fiesta en la habitación de al lado (2007, Erein), ha vuelto a destapar viejos fantasmas.

El futuro de la literatura vasca pasa por la aceptación de que aunque el euskara sea la marca de identidad más definitiva para muchos de nosotros, también las otras lenguas que nos habitan pueden convertirse con naturalidad lenguas para la creación literaria. A esta opción habrá que añadir una tercera vía en la que los creadores vascos podrán criollizar la lengua vasca, mostrar su identidad híbrida, identidad que de momento, excepto en narraciones como Dos letters (1990) de Atxaga, no se ha presentado en nuestra literatura actual.

\section{Para terminar: Las literaturas que hemos «ganado». Breve repaso a la literatura vasca traducida y sus ansiedades}

Llegados a este punto, quisiéramos completar esta reflexión en torno a la creación en lengua vasca con algunas consideraciones en torno a la traducción. Se trataría de dar los primeros pasos para una investigación de la evolución del pro- 
ceso de autonomización que ha sufrido la literatura escrita en lengua vasca. Autonomización que pasa por las traducciones a otras lenguas más centrales pues son, precisamente, estas traducciones las que permiten obtener el certificado literario para una literatura minoritaria. Como defendió Casanova (2001: 182-3), la traducción, además de una naturalización (en el sentido de cambio de nacionalidad), supone una literarización, un imponerse como literatura ante instituciones legitimadoras. Las líneas que siguen presentarán una breve reflexión en torno a la función que la literatura traducida (del euskara, al euskara) tiene en nuestro sistema literario. Lejos quedaron los tiempos en que una mentira, la de J. B. Dasconaguerre al afirmar que su novela Les Echos du pas de Roland (1867) había sido traducida del euskara, sirvió para aliviar, aunque por poco tiempo, la ansiedad por incorporar a nuestra historia literaria un género, la novela, que no tuvo su verdadero nacimiento hasta 1898. Lo que el escritor Ramón Saizarbitoria ha llamado «alucinación narcisista» (Saizarbitoria 1999) no es más que un episodio más del recurrente debate en torno a la capacidad de la lengua vasca para crear universos de ficción.

Sea como fuere, si hay algo que resulta incuestionable es la calidad que la lengua literaria vasca ha adquirido gracias al buen quehacer de los traductores vascos. Las funciones que esta literatura traducida ha cumplido en nuestra lengua se resumirían, según el profesor Manu López Gaseni (2008) en «la creación de un lenguaje literario autóctono, la aportación de repertorios literarios de los que la literatura vasca carecía previamente, y la renovación de determinados modelos que comenzaban a resultar caducos». Esta importante función que la literatura traducida ha tenido para la literatura en lengua vasca estaría en consonancia con la centralidad que Even Zohar le atribuye a la literatura traducida en sistemas literarios débiles:

(a) when a polysystem has not yet been crystallized, that is to say, when a literature is «young,» in the process of being established; (b) when a literature is either «peripheral» (within a large group of correlated literatures) or «weak,» 1 or both; and (c) when there are turning points, crises, or literary vacuums in a literature. (1990: 47)

En opinión de la doctora M. Dominguez (2008), ésta es la función que todavía las traducciones tienen en algunas literaturas del ámbito ibérico, tales como la vasca y gallega ${ }^{8}$. En el caso de la literatura vasca, habría que subrayar que el convenio que la Asociación de Traductores, Intérpretes y Correctores de la Lengua Vasca, EIZIE (1987), firmó con el Gobierno Vasco en 1989 para poner en marcha la colección «Literatura Unibertsala» de obras universales traducidas al euskara, ha incidido positivamente en la legitimización de la labor del

${ }^{8}$ En cualquier caso, deberíamos precisar que la incidencia de las traducciones en la literatura infantil y juvenil sigue siendo mayor que en la tradicionalmente considerada «literatura de adultos». M. Dominguez (2008:16) afirma que en la década de los 1990 «el porcentaje de LIJ traducida rondaba el $50 \%$ de la producción de LIJ en España, y era el sector de LIJ que más se leía (Pascua y Gisela Marcelo 2000: 212)». Ese porcentaje ha ido decreciendo y según los datos del INE (cit. Dominguez: 2008), entre 1999 y 2002 era del $15,28 \%$. 
traductor para la renovación y la normalización de la lengua literaria vasca. Dicha colección incluye hasta la fecha 143 títulos. Lo mismo podríamos decir a propósito de otra colección, Pentsamenduaren Klasikoak (Clásicos del Pensamiento), que inició su andadura allá por 1991. Todo este corpus, unido al que han ido conformando las colecciones de novela negra de editoriales vascas como Igela, o Elkar, por citar solo algunos ejemplos, han puesto al alcance del lector vasco traducciones de calidad de autores canónicos universales como Eliot, Faulkner, Dostoyevsky, Maupassant, Queneau, o Barthes, obras que sin duda han enriquecido el repertorio literario contemporáneo de obras vascas. Es evidente que la institución literaria vasca ha legitimado la importancia que la traducción tiene para la literatura en lengua vasca, sea por medio de los Premios Euskadi de Traducción (1997-), sea con la instauración de la Licenciatura de Traducción e Interpretación en la Universidad del País Vasco (2000). Pero, ¿quiere ello decir que en el sistema literario vasco las traducciones tienen una centralidad que no tienen en otros sistemas? A falta de un estudio riguroso que permita ofrecer datos fehacientes de tiradas, ventas, o procesos de canonización, la sospecha es que las traducciones tienen una aceptación muy limitada entre los lectores vascos, y que su impacto real fuera del circuito escolar es muy limitado (cf. Olaziregi 1999). Y todo ello en un contexto donde el consumo cultural en euskara sigue siendo bajo y preocupante. Según Kultura 07 (Publicación del Observatorio de la Cultura del Gobierno Vasco, noviembre del 2007), el $67 \%$ de los habitantes de la Comunidad Autónoma Vasca no lee un solo libro/periódico/revista en euskara al año. La cifra se eleva al 78\% en Iparralde, y al $83 \%$ en Navarra. Aunque las últimas décadas han conocido un claro incremento del número de vascoparlantes (hace algunos años se hablaba de unos 100.000), creo que es evidente que el impacto de éstos en el consumo de la literatura vasca no ha sido el esperado. Quizás ello tenga que ver con lo que el escritor Anjel Lertxundi calificaba como «un déficit en la transmisión de la lengua» (Etxeberria 2002: 193), o con «la crisis del modelo de vascoparlantes, de los lectores» (Etxeberria 2002: 194). El hecho de que los jóvenes vascos que han estudiado en euskara hasta completar la Educación Secundaria en euskara tengan dificultades para leer literatura vasca, o que sus hábitos de lectura en euskara decrezcan al finalizar la educación secundaria, es más que significativo. Dicho de otro modo: las conclusiones a las que llegamos en nuestro estudio sociológico de los hábitos de lectura de los jóvenes vascos en 1996 necesitarían ser refutadas o confirmadas (cf. Olaziregi: 2000).

En cuanto a las traducciones de obras escritas originariamente en euskara a otras lenguas, la verdad es que de momento no poseemos un estudio exhaustivo de la evolución de las mismas. En la actualidad, calculamos que el número de títulos traducidos del euskara a otras lenguas rondará los 200 (cf. www.basqueliterature.com). Pero de lo que no hay duda es de que ya desde la década de los años 1960 la institución literaria vasca estaba convencida de la importancia que la traducción a otras lenguas tenía para la supervivencia del euskara y para la profesionalización de nuestros escritores (cf. Olaziregi, M.J. 2001). Lo cierto es que el incremento del número de títulos traducidos del euskara a otras lenguas ha seguido un ritmo muy lento y no ha sido hasta finales del siglo XX cuando de verdad se ha confirmado esta tendencia. Además de la tra- 
yectoria que la obra de Mariasun Landa ha tenido fuera de nuestras fronteras, es obvio que ha sido Bernardo Atxaga quien ha marcado un antes y un después en la proyección internacional de nuestra literatura (cf. Olaziregi, M.J: 2005). Obabakoak (1988) con sus veintiséis traducciones constituye un hito en nuestra historiografía literaria, pero no sólo eso, ya que la trayectoria de Atxaga se constituyó para muchos autores vascos un modelo a imitar, un modelo que, sea dicho de paso, generó cierta ansiedad por «homologar» nuestra literatura y situarla en el mapa del panorama mundial actual. Joan Mari Torrealdai (2007), conocido sociólogo y estudioso de la cultura vasca, diagnosticaba que la cultura vasca sufre de lo que denominaba el «síndrome kanpoeder» (síndrome «todo lo de fuera es bueno»). Es decir, una creencia enfermiza de que todo lo de fuera es bueno y nos homologa. Como ejemplo, Torrealdai citaba el caso del Museo Guggenheim en Bilbao.

Personalmente, no creo que diagnósticos de este tipo tengan nada que ver con una reflexión rigurosa sobre las consecuencias de la traducción y promoción internacional de la literatura vasca. En realidad, es evidente que el modo en el que nos hemos movido fuera de nuestras fronteras ha sido muy «amateur». A falta de una institución vasca que promueva y promocione nuestra literatura en el exterior, han sido los contactos directos con editoriales e instituciones extranjeras, o los premios literarios de prestigio los que han servido para «lanzar» algunos de los escritores en lengua vasca. El Gobierno Vasco no ha subvencionado la traducción y promoción de la literatura vasca hasta el año 2000, y la presencia de nuestra literatura en foros como la Feria de Frankfurt, aunque necesaria, no ha generado la curiosidad deseada hasta ahora. Incluso proyectos como el que la Asociación de Escritores en Lengua Vasca (1982), EIE, trató de impulsar a partir del 2003 bajo la denominación de ELAP (Euskal Literatura Atzerriratzeko Plana-Plan para Promocionar la Literatura Vasca en el Extranjero), o el Committee to Promote Basque Literature, que se creó al amparo de la organización europea LAF (Literature Accross Frontiers) en el 2005, no son más que ejemplos de esas iniciativas «amateurs» atomizadas que han pretendido subsanar la debilidad de la institución literaria vasca y responder a la demanda de los propios autores y críticos vascos. Lo que sí ha permitido la entrada en el siglo XXI es afianzar el corpus de traductores que tienen la competencia literaria y lingüística suficiente para traducir del euskara a otras lenguas, sin pasar por «lenguas puente». La colección que desde el Center for Basque Studies de la University of Nevada, en Reno, creamos en el año 2004 se inscribe en esta línea, y su primer título: An Anthology of Basque Short Stories (2004) es un ejemplo de ello. Los cuentos vascos que integran el volumen fueron traducidos directamente al inglés. Las traducciones posteriores que ha tenido la antología citada (al español: Lengua de Trapo, 2005; Círculo de lectores, 2008; al ruso, U. Of St. Petersburg, 2006; al italiano: Gran Vía, 2007), así como la reedición en inglés por parte de la editorial comercial británica, Parthian, confirman el lugar hegemónico y central que ocupa la lengua inglesa en el mercado global, y la ayuda que dicha centralidad puede traer para superar la «invisibilidad» de lenguas minoritarias como la nuestra.

De lo que no hay ninguna duda es de la dependencia que el sistema literario vasco tiene del sistema central del espacio ibérico, es decir, del castellano. Y en 
este punto deberíamos precisar que nos unimos a las voces que en la reciente historiografía literaria española han abogado por la necesidad de estudiar las relaciones entre las diversas literaturas del estado español y por superar el «ethnic, linguistic and cultural homogeneity» (Cabo 2001) de la que ha partido hasta la fecha la historiografía literaria española canónica. Para ello, resultan más que prometedoras las propuestas que investigadores de la Universidad de Santiago de Compostela como A. Casas (2003) han realizado a partir de conceptos como «sistema interliterario ibérico» (Zohar), y «comunidad interliteraria» ( Dionyz Durisin). Otras publicaciones, como las incluidas en el volumen colectivo: Spain Beyond Spain (Epps and Fdez. Cifuentes, eds., 2005), han defendido un enfoque que superaría el concepto monolingüe del estado español «by delving into either the place of the so-called peripheral languages and literatures (Catalan, Galician, and Basque) or the place of emigrants and exiles in Spanish literary history» (op. cit., p. 20).

Los resultados obtenidos en su estudio por el profesor Andreu van Hooft (2004) me parecen más que reseñables a la hora de iniciar una reflexión en torno a las relaciones jerárquicas y las interferencias entre las diversas literaturas del ámbito ibérico. Hooft describe el espacio intercultural español del período 1990-1998 como muy desequilibrado debido a la prevalencia que la lengua castellana tenía sobre las demás. Podría afirmarse que el castellano ha funcionado como lengua franca. Los resultados no cambiarían demasiado para el período 1999-2003: los sistemas catalán, gallego y vasco continúan vertiendo gran proporción de obras al castellano (en el caso vasco alcanza el $88 \%$, frente al $12 \%$ de obras traducidas del euskara al catalán y gallego). Es reseñable que es el sistema literario vasco el que tiene más talante intercultural, es decir, el que mayor proporción de obras traduce a las otras lenguas del estado, aunque lo que resulta realmente llamativo es el ínfimo volumen de obras que se traducen del castellano al resto de las lenguas del estado español. Frente a 317 títulos de obras escritas en euskara, catalán y gallego traducidas al castellano en el período 1999-2003, tenemos sólo 20 títulos traducidos a las lenguas minoritarias.

A pesar de los datos reseñados, Hooft (2004: 330) sí aprecia una notable corriente de construcción de un espacio literario intercultural. Las antologías de poesía y narrativa publicadas en las últimas décadas, o el número de escritores que ha visto su obra publicada en varias lenguas del estado español así lo corroboran. Según Hooft (2004:330), dos autores vascos, Bernardo Atxaga y Unai Elorriaga, son el mejor exponente de escritores que facilitan la existencia de un espacio intercultural al publicar sus textos en las cuatro lenguas del estado 9 . Esta práctica, la de traducir las obras a todas las lenguas del estado español, está más extendida en el ámbito de la literatura infantil y juvenil ${ }^{10}$. Por otro lado, no está de más recordar, al hilo de lo afirmado por el profesor Mario Santana (2009), que de los

\footnotetext{
${ }^{9}$ El panorama es similar en el ámbito de la literatura infantil y juvenil, según se deduce de los datos aportados por M. Domínguez (2008).

10 Como destaca Mónica Domínguez (2008), esta práctica es común en las colecciones «El barco de vapor» (SM), «Infantil Alfaguara» (Alfaguara) y «Ala delta» (Edelvives), entre otras. También es destacable la colección «La chalupa»/《La xalupa»/《Txalupa $» / « A$ chalupa», impulsada por las editoriales: La Galera, Elkar y Galaxia.
} 
121 libros de narrativa que han sido galardonados con el Premio de la Critica desde el año 1976 en España, El hijo del acordeonista de Atxaga es el único libro que ha sido traducido a todas las lenguas del estado español. Hecho que resulta llamativo por cuanto hablamos de un premio creado para impulsar las relaciones entre las literaturas de las cuatro lenguas del estado español, impulso que lejos de imponerse ha servido para poner de manifiesto cuestiones relevantes a la invisibilidad/visibilidad de las lenguas minoritarias del estado y el poder del sistema literario central.

Una no puede resistirse a la tentación de parafrasear el conocido verso que Gabriel Aresti escribiera en homenaje al socialista bilbaíno Tomás Meabe («Es verdadero español/ quien sabe las cuatro lenguas de España»), e ironizar sobre la contribución que la literatura vasca está realizando a la conformación de un espacio interliterario ibérico. En cualquier caso, los porcentajes que hemos presentado y comentado deberían ser completados con los procesos de invisibilización que se están dando hacia las literaturas periféricas en el ámbito español por parte de la literatura central, la española. Los problemas que hay en la base de datos del ISBN para delimitar la lengua original de los textos, la omisión en los créditos del título original en euskara...son sólo algunos de los procesos que en el caso de autores vascos como Atxaga se están dando constantemente (cf. Hooft, cf. López Gaseni).

Creo que deberíamos hacer un breve apunte sobre las traducciones al castellano que editoriales vascas como Hiru, Erein, Alberdania, o Ttarttalo han impulsado a partir de la década de los años 90 . Aunque se distribuyan a nivel estatal, lo cierto es que dichas publicaciones tienen su mercado potencial más próximo en la comunidad castellanoparlante vasca. Las constantes manifestaciones de los autores vascos en torno a la escasa curiosidad que estas traducciones despiertan entre sus conciudadanos (véase, por ejemplo, las declaraciones de Harkaitz Cano, Jon Alonso y Juan Luis Zabala en la revista Senez (n. 32, 2007, Febrero del 2008. Cf. www.eizie.org), hablan de la clara incomunicación, de la «guettización» (término utilizado todavía en este tipo de debates), que sufre, en opinión de algunos, la literatura escrita en lengua vasca en Euskal Herria. Sólo nos queda desear que en un futuro no muy lejano dichas barreras sean superadas y que la literatura escrita en lengua vasca se erija en vía de comunicación entre las diversas comunidades lingüísticas.

\section{BIBLIOGRAFÍA}

Abuín GonzÁlez, Anxo and Anxo Tarrío Varela (eds.), Bases metodolóxicas para unha historia comparada das literaturas da península Ibérica. Santiago de Compostela: Servicio de Publicaciones de la Universidad de Santiago de Compostela, 2004.

AlDEKOA, Iñaki, Historia de la Literatura Vasca. Donostia: Erein, 2004.

Altan, Ahmet, et al. Debout dans Babel. Langues en Europe. Rekkem (Belgium): «Ons Erfdeel vzw,» 2007.

ANDERson, Benedict, Imagined Communities. London: Verso, 1991.

ARESTI, Gabriel. Artikuluak. Hitzaldiak. Gutunak. Zarautz: Susa, 1986. 
ArкотхA, Aurelia and Beñat Oyharçabal, «Las primicias de las letras vascas.» http://www.basqueliterature.com/literatura.

AtXAGA, Bernardo, «Otra mirada.» www.atxaga.org/testuak-textos/otra-mirada.

—, El hombre solo. Barcelona: Ediciones, B., 1993.

—, Esos cielos. Barcelona: Ediciones, B., 1995.

—, El hijo del acordeonista. Madrid: Alfaguara, 2004.

BARbeito, José Manuel; JAIME FeiJoo, Antón Figueroa, and Jorge Sacido (eds.), National Identities and European Literatures. Bern: Peter Lang, 2008.

BнABHA, Homi, The Location of Culture. London: Routledge, 1994.

CABo Aseguinolaza, Fernando, «Dead, or a Picture of Good Health? Comparatism, Europe, and World Literature,» Comparative Literature, 58.4, Fall 2006: 418-435.

—, «National Canon Formation as Interliterary Process: The Spanish Case» [online]. $\mathrm{Li}$ terary Research/Recherche littéraire: 18 (35), 51-62. Ibid. <http://collection.nlcbnc.ca/100/201/300/literary_research-ef/n28-n36/old35/ArticlesCabo.htm>

Casanova, Pascale, La República mundial de las Letras. Barcelona: Anagrama, 2001.

CASAS, Arturo, «Sistema interliterario y planificación historiográfica a propósito del espacio geocultural ibérico.» Interlitteraria 8 (2003): 68-97.

CRYSTAL, David, The Language Revolution. Cambridge: Polity Press, 2004.

DomíngueZ, Mónica, «Las traducciones de la literatura infantil y juvenil en el interior de la comunidad interliteraria específica española (1940-1980.)». Tesis doctoral inédita. Universidad de Santiago de Compostela, 2008.

EpPs, Brad, and Luis Fernández CifuENTEs (eds.), Spain Beyond Spain. Lewisburg: Bucknell University Press, 2005.

EtXEBERRIA, Hasier (ed.), Cinco escritores vascos. Entrevistas de Hasier Etxeberria, Irun: Alberdania, 2002.

Even-Zohar, Itamar, «Polysystem Studies,» Poetics Today 11.1 (1990): 97-194.

—, «A Función da literatura na creación das nacións de Europa.» Grial XXXI.120 (1993): 441-58.

FigueroA, Antón, Diglosia e texto. Vigo: Xerais, 1988.

Hooft Comajuncosas, Andreu van (2004), «¿Un espacio literario intercultural en España? El polisistema interliterario en el estado español a partir de las traducciones de las obras pertenecientes a los sistemas literarios vasco, gallego, catalán y español (1999-2003).» Bases metodolóxicas para unha historia comparada das literaturas da península Ibérica. Ed. Abuín González Anxo and Anxo Tarrío Varela. Santiago de Compostela: Servicio de Publicaciones de la Universidad de Santiago de Compostela, 2004. 313-333.

JUARISTI, Jon, Literatura vasca. Madrid: Taurus, 1987.

LASAgabaster, Jesús María, Las literaturas de los vascos. Donostia: Universidad de Deusto, 2002.

—, «La Ilustración en la vida literaria vasca del siglo XVIII.» Lapurdum IX (2005): 149-157.

LERTXUNDI, Anjel, Koldo Mitxelena entre nosotros. Irun: Alberdania, 2001.

LÓPEZ GASENI, Manuel, «Literatura traducida.» www.basqueliterature.com/basque/ his$\underline{\text { toria/itzulia, } 2008 .}$ 
MAAlouf, Amin, Identidades asesinas. Madrid: Alianza, 1999.

Martín Gaite, Carmen, Usos amorosos del dieciocho en España, Barcelona: LUMEN, 1981.

MERCERo, Gorka, «Bernardo Atxagaren Soinujolearen semea: nazioari mugak non ezarri erabakitzearen ezintasuna.»Lapurdum XI (2006): 241-270.

Müller, Jan-Werner, ed. Memory and Power in Post-War Europe. Studies in the Presence of the Past. Cambridge: Cambridge University Press, 2002.

OlAZIREGI, Mari Jose. «Aproximación sociológica a los hábitos de lectura de la juventud vasca.» Oihenart 18 (2000): 79-93.

- Waking the Hedgehog. The Literary Universe of Bernardo Atxaga. Reno: Center for Basque Studies and University of Nevada-Reno, 2005.

-, «Basque Fiction.» A Companion to the Twentieth-Century Spanish Novel. Ed. Marta E. Altisent. Woodbridge: Tamesis, 2008. 247-258.

OTAEGI, Lourdes, «Poesía vasca del siglo XX,» www.basqueliterature.com/historia.

SAIZARbitoria, Ramon, Aberriaren alde (eta contra). Irun: Alberdania, 1999.

-, Gorde nazazu lurpean. Donostia: Erein. Castellano: Guárdame bajo tierra, traducido por Eguia Careaga, Madrid: Alfaguara.

SantanA, Mario, «On Visible and Invisible Languages: Bernardo Atxaga's Soinujolearen semea in Translation», en Mari Jose Olaziregi (Ed.)., Writers in Between Languages: Minority Literatures in the Global Scene, Reno, Center for Basque Studies-University of Nevada, Reno, 2009.

Serrano Izko, Bixente, et al. Pío Baroja, 50 urte. Iruña: Ayuntamiento de Iruña, 2007.

SubIRANA, Jaume, «National Poets and Universal Catalans. Writers and Literature in Contemporary Catalan Identity.» National Identities and European Literatures. Ed. José Manuel Barbeito, Jaime Feijoo, Antón Figueroa, and Jorge Sacido. Bern: Peter Lang, 2008. 247-266.

Torrealdai, Joan Mari, La censura de Franco y el tema vasco. Donostia: Kutxa, 1999.

—, 30 urte liburugintzan: 1976-2005. Donostia: Jakin, 2007.

URKIZA, Ana, Zortzi unibertso. Zortzi idazle. Irun: Alberdania, 2006.

Woodworth, Paddy et al, Capital creativo, Mondragón, MIK, 2007.

ZalduA, Iban, «Bibliografía». Pintxos. Nuevos cuentos vascos, Ed. Mari Jose Olaziregi. Madrid: Lengua de Trapo, 2005. 
